\title{
D-quantification: A Japanese Variation
}

\author{
Shinobu Mizuguchi ${ }^{*}$ \\ LSA Annual Meeting, Minneapolis, January 2-5, 2014
}

I. Introduction. Determiner quantifiers like every and most are assumed to take common noun phrases of type $<\mathrm{e}, \mathrm{t}>$ to derive a generalized quantifier of type $<<\mathrm{e}, \mathrm{t}>, \mathrm{t}>$, as in (1). Matthewson 2001 subjects this standard assumption to crosslinguistic scrutiny, and based on St'át'imcets (Lillooet Salish), she proposes a two-step approach to create a QP; the first is the creation of a DP of type $<\mathrm{e}>$ and the second involves quantification over parts of the plural individual denoted by the DP, as illustrated in (2).

(1)

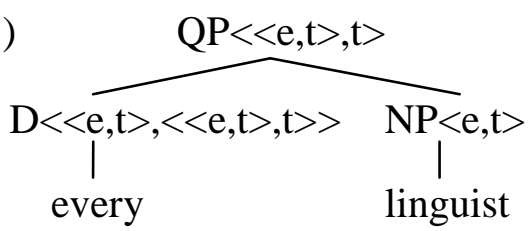

(2)

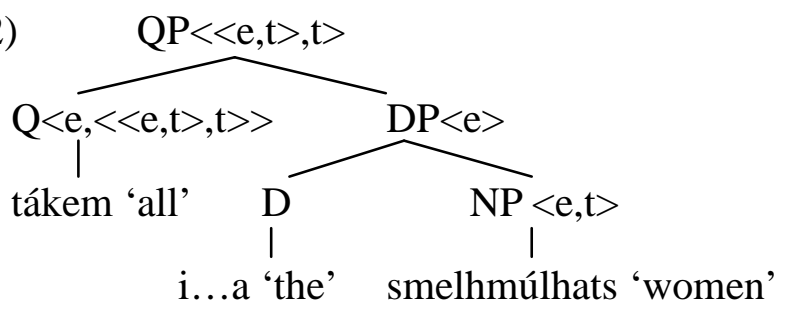

This paper discusses Japanese, which lacks D and has nouns of type $<\mathrm{e}>$ (cf. Chierchia 1998, Mizuguchi 2004). Japanese allows 'double quantification', which, I argue, is best explained if Japanese nouns remain of type $<\mathrm{e}>$ throughout the derivation.

II. Basic Japanese Facts. Japanese is a numeral classifier language and nouns appear bare, with no determiners and no number marking. Bare nouns have the full range of readings of DPs, i.e. definite, indefinite, narrow and wide scope, generic, and existential; gakusei, for instance, means 'the student/a student/student(s)/the students', depending on the context.

Japanese has a variety of quantifiers: pre-nominal (rough equivalent to D-quantifiers), floating, and adverbial quantifiers (A-quantifiers, for short). It has $\mathrm{WH}$ - indeterminate constructions with quantificational force: the existential force with focus particle $K A$, the universal force with $M O$, and the free choice force with $D E M O$.

$$
\begin{aligned}
& \text { Pre-nominal quantifier: Subete-no michi-wa Roma-ni tsuzu. } \\
& \text { all-GEN road-TOP Rome-LOC lead } \\
& \text { 'All the roads lead to Rome.' } \\
& \text { Floating quantifier: Murabito-ga hotondo atsumat-ta. } \\
& \text { villager-NOM most gather-PAST } \\
& \text { 'Most villagers gathered.' }
\end{aligned}
$$

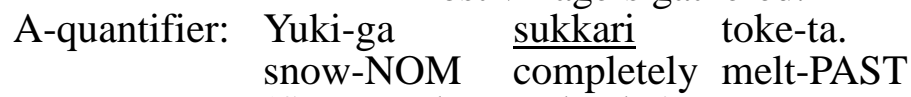

$$
\begin{aligned}
& \text { 'Snow melt completely.' } \\
& \text { WH-indeterminate: Dare-ka/mo-ga/demo ki-ta. } \\
& \text { who-KA/MO-NOM/DEMO come-PAST } \\
& \text { 'Lit. Somebody/Everybody/Anybody came.' }
\end{aligned}
$$

Quantifiers like arayuru 'every', $k a k u$ 'each/all', and dono'which'-N-mo appear pre-nominal only (cf. (7) - (9)), and $\min ($ ' $n$ ) $a$ 'all' is restricted to the post-nominal adjunct position (cf. (8),(10)). Most Japanese quantifiers, however, can float, contra English (cf. Schwarzschild

* Kobe University (mizuguti@kobe-u.ac.jp). I'd like to express my gratitude to the audience of the poster session of LSA 2014, whose comments have led me to improve the earlier version of this abstract. The remaining errors are, of course, all mine. 
1996), and appear both pre-nominally and post-nominally (cf. hotondo 'most' in (4) and (10)).

(7) $\quad \begin{array}{lll}\text { Arayuru-toi-ni } & \text { (subete) } & \text { kotaeru. } \\ \text { all-question-LOC } & \text { (all) } & \text { answer }\end{array}$

'(I) answer all the questions.'

(8)
Kaku-jin-ga
(mina)
every-human-NOM (all)
chigau-taikei-o
motteiru.

'Every person has a different system.'

(9) Dono-sakuhin-mo (zenbu) rikisakuda.

Which-work-MO all outstanding

'Every piece of work is outstanding.'

(10)

$\begin{array}{lllll}\underline{\text { Hotondo-no }} & \text { koto-wa } & \underline{\text { (min’na) }} & \text { kikai-ga } & \text { yattekureru. } \\ \text { most-GEN } & \text { issue-TOP } & \text { all } & \text { machine-NOM } & \text { do }\end{array}$

'Lit. Machines do (all of) most issues.'

A puzzle is why Japanese allows most quantifiers to float, and another puzzle is why Japanese allows ‘double quantification’, as in (7) - (10).

III. Proposal. Gunji and Hasida 1998 argue that post-nominal floating quantifier san-ton 'three tons' in (11b) is an incremental theme in the sense of Dowty 1991 and measures the event denoted by the verb indirectly; the event of tokeru 'melt' is subject to measurement, while that of oshitsubusu 'smash' is not.
a. San-ton-no yuki-ga toke-ta/ie-o
oshitsubushi-ta.
Three-ton-GEN snow-NOM melt-PAST/house-ACC
smash-PAST
'Three tons of snow melted/smashed the house(s).'

b. Yuki-ga san-ton toke-ta/*ie-o oshitsubushi-ta. (Gunji and Hasida 1998: 61)

Based on Gunji and Hasida 1998, I propose (i) pre-nominal 'quantifiers' are not genuine quantifiers but generate a set of subsets i.e. a cover in the sense of Schwarzschild 1996, as defined in (12), and (ii) post-nominal quantifiers quantify over the cover generated.

$$
\text { For } \left.\left.[[\alpha]]^{\mathrm{g}} \subseteq \mathrm{D}_{\mathrm{e}} \text {, [[Pre-nominal } \mathrm{Q} \alpha\right]\right]^{\mathrm{g}}=\lambda \mathrm{P}[\forall \mathrm{x}[(\operatorname{Cov}(\mathrm{x}) \wedge(\mathrm{x} \subseteq \alpha)) \rightarrow \mathrm{P}(\mathrm{x})]]
$$

Pre-nominal 'quantifiers' are not a quantifier but a cover, i.e. a set of sets. In 'double quantification', as given in (7) - (10), pre-nominal 'quantifiers' specify only the range of quantifiers to scope over. Post-nominal floating quantifiers are genuine quantifiers and they therefore occur with accomplishment verbs like tokeru 'melt' in (11b). Pre-nominal san-ton 'three tons' in (11a) is not a quantifier and appear with achievement verbs like oshitsubusu 'smash'. Japanese has many cover-generators which are restricted to appear pre-nominal only (cf. (13c)).
a. Tairyo-no mizu-o non-da. much-GEN water-ACC drink-PAST
'Lit. (I) drank much water.'
b. *Mizu-o tairyo non-da.
c. pre-nominal only: tai-ryo 'much', ka-han 'more than half', han-su 'half', sho-su 'a small number', mu-su 'coutless', etc.

Another piece of evidence to support my claim comes from the fact that only post-nominal floating quantifiers are scrambled to the sentence-initial position. Compare (11) with (14). 

a. $\quad$ Min'na $_{\mathrm{i}} /$ Hotondo $_{\mathrm{i}} /$ San-ton $_{\mathrm{i}}$
yuki-ga
$\mathrm{t}_{\mathrm{i}}$ toke-ta.
all/most/three-ton
snow-NOM
melt-PAST

'All/Most/Three tons of snow melt.'

b. San-ton-no yuki-ga min'na/hotondo toketa.

'All/Most of the three tons of snow melted.'

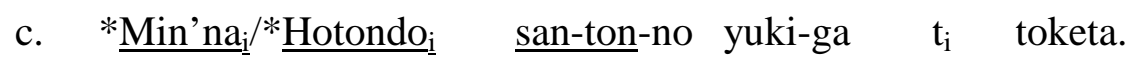

Miyagawa 1989 argues Japanese floating quantifiers and their heads/traces are subject to a syntactic mutual c-command constraint (cf. (14a)). Ishii 1999 further argues that Miyagawa's requirement is not enough; only floating 'VP quantifiers' (i.e. 'incremental theme' in our terminology), are subject to scramble to the sentence-initial position. (14c), however, shows that even Ishii's analysis is not borne out. (14c) is unacceptable since floating quantifiers min'na/hotondo 'all/most' precede the range of scope to quantify over.

Possible counterarguments would come from the traditional analysis of $\mathrm{WH}$-indeterminate $M O$ as the universal operator, as given in (15).

$$
\begin{aligned}
& \text { For }[[\alpha]]^{\mathrm{g}} \subseteq \mathrm{D}_{\mathrm{e}},[[\alpha \mathrm{mo}]]^{\mathrm{g}}=\lambda \mathrm{P} \forall \mathrm{x}\left[\mathrm{x} \in[[\alpha]]^{\mathrm{g}} \rightarrow \mathrm{P}(\mathrm{x})=1\right] \quad \text { (Shimoyama 2006: 155) } \\
& \text { [Dono-kago-no-[ringo]-mo] (hotondo/ik-ko) kusatteisu. } \\
& \text { which-basket-GEN-apple-MO (most/one-CL) re rotten } \\
& \text { 'Most apples/An apple of each basket are/is rotten.' }
\end{aligned}
$$

Sentences like (16) show that (15) is too strong; ringo 'apple' in (16), though it is in the scope of $M O$, has the proportional and the existential reading. In my analysis, it is kago 'basket' in (16) that generates a cover, and ringo 'apple' stays as the whole set, which is subject to quantification, independently from kago 'basket'. The difference between my analysis and the traditional analysis lies in what pre-nominal 'quantifiers' generate: cover of type $<\mathrm{e}>$ in the former and member in the latter. (16) is best explained if ringo 'apple' remains of type $<\mathrm{e}>$.

Another counterexample would be that examples like (7)-(10) were partitives. This argument is, however, not borne out; $\min ($ 'n)a 'all', for example, cannot be a partitive head noun in Japanese.

IV. Cross-linguistic Perspective and Implications. Chinese also has the phenomenon of 'double quantification'.

$\begin{array}{lll}\text { Mei-ge/Dabufen-de/Suoyou-de } & \begin{array}{l}\text { ren } \\ \text { person }\end{array} \\ \text { each-CL/most-of/all-of } & *\left(\frac{\text { dou })}{\text { all }}\right. & \begin{array}{l}\text { lai-le } \\ \text { come-PERF }\end{array} \\ \text { cLit. Each/Most/All of the people all came.' } & \end{array}$

Unlike Japanese, post-nominal floating dou 'all' is obligatory in Chinese. In the Chinese literature, dou is analyzed as the universal operator (cf.Cheng 1995), sum operator (cf. Huang 1998), generalized distributor (cf. Lin 1998) and maximality operator (cf. Xiang 2008). These analyses need to explain why dabufen 'most' and dou 'all' are semantically compatible. In my analysis, dou is the universal quantifier and pre-nominal mei-CL/dabufen/suoyou are cover-generators.

If I am on the right track, I need to see whether my analysis fits into the general picture of quantifiers. Since Japanese and Chinese are classifier languages and lack D, they do not go into the generalized quantifier framework like (1) or (2); pre-nominal 'quantifiers' look similar to D-quantifiers in determiner-rich languages like English and French, but I have discussed in this paper that they are not quantifiers but cover-generators. It is floating quantifiers that are genuine quantifiers in D-lacking bare noun languages. Syntactically they are adjuncts and are subject to scramble in Japanese (cf. (14a)). Semantically they quantify 
over the whole set (cf. (4), (11b), (14a)) or the cover generated by pre-nominal 'quantifiers' (cf. (7) - (10), (14b)). On the assumption that the basic noun type is $<\mathrm{e}>$ or kinds in [+arg, -pred] languages (cf. Chierchia 1998), Japanese nouns remain of type $<\mathrm{e}>$ throughout the derivation. A possible counterargument comes from WH-indeterminate- $M O$ construction like (16), where ringo 'apple' is an individual, not a kind. A further look, however, shows that WH-MO is compatible both with kinds and individuals, as observed in (18a,b).
a. Dono-kyoryu-mo (min'na) zetsumetushi-ta. which-dinosaur-MO all be extinct-PAST 'Lit. Every disnosaur was all extinct.'
b. Dono-ko-mo (min'na) genkida. which-child-MO all be in good spirits 'Lit. Every child is all in good spirits.'

Chierchiea 1998 proposes the Up operator to instantiate individuals from kinds, but it is not clear whether Japanese uses the Up operator, since Japanese nouns type-shift covertly, like Dënesųiné (Northern Dene/Athabaskan), which uses a realization relation $\mathrm{R}$ to instantiate kinds as individuals (cf. Wilhelm 2014). In this light, D-lacking bare noun languages generate QPs out of nouns of type $<\mathrm{e}>$ directly, while D-rich languages need Ds to generate DPs of type $<\mathrm{e}>$ from NPs of type $<\mathrm{e}, \mathrm{t}>$ and then generate QPs.

Though this cross-linguistic picture needs further scrutiny, it looks fit well in the traditional semantics of quantifiers based on sets.

\section{References}

Cheng, Lisa Lai-Shen. 1995. On dou-quantification. Journal of East Asian Lingusitics 8. 197-234.

Chierchia, Gennaro. 1998. Reference to kinds across languages. Natural Language Semantics 6. 339-405.

Dowty, David. 1991. Thematic proto-roles and argument selection. Language 67. 547-619.

Gunji,Takao and Koichi Hasida. 1998. Measurement and quantification, in Takao Gunji \& Koichi Hasida (eds.). Topics in Constraint-based Grammar of Japanese. 39-79. Dordrecht: Kluwer.

Huang, Shi-Zhe. 1996. Quantification and Predication in Mandarin Chinese: A Case Study of DOU. University of Pennsylvania dissertation.

Ishii, Yasuo. 1999. A note on floating quantifiers in Japanese. In Masatake Muraki \& Enoku Iwamoto (eds.). Lingusitics: In Search of the Human Mind. 236-267. Tokyo: Kaitakusha.

Lin, Jay.-Wong. 1998. Distributivity in Chinese and its implications, Natural Language Semantics 6. 201-243.

Matthewson, Lisa. 2001. Quantification and the nature of crosslinguistic variation. Natural Language Semantics 9. 145-189.

Miyagawa, Shigeru. 1989. Structure and Case Marking in Japanese. Syntax and Semantics 22. San Diego: Academic Press.

Mizuguchi, Shinobu. 2004. Individuation in Numeral Classifier Languages. Tokyo: Shohakusha..

Schwarzschild, Roger. 1996. Pluralities. Dordrecht: Kluwer.

Shimoyama, Junko. 2006. Indeterminate phrase quantification in Japanese, Natural Language Semantics 14. 139-173.

Wilhelm, Andrea. 2014. A radically [+arg, -pred] languages. Paper read at Semantics of Under-Represented Language in the Americas (SULA) 8. May 2014. University of British Columbia.

Xiang, Ming. 2008. Plurality, maximality and scalar inferences: A case study of Mandarin dou. Journal of East Asian Linguistics 17. 227-245. 